\title{
Techniques to Mitigate Problem of Partial Shading and Soiling on PV Module: A Review
}

\author{
Aemal Ahmad ${ }^{1}$, Muhammad Arif Khattak ${ }^{2}$, Muhammad Zeeshan ${ }^{3}$, Muhammad Salman $^{4}$, Kamran Alam $^{5}$ \\ 1,2,3,4,5 U.S.-Pakistan Center for Advanced Studies in Energy (USPCAS-E), University of Engineering and Technology \\ Peshawar, Pakistan \\ *Corresponding author: Aahmad14@asu.edu ${ }^{1}$ \\ Received: 09 April, Revised: 17 April, Accepted: 24 April
}

\begin{abstract}
Power output of a pv module strongly depends on the irradiance it receives. There are many factors which limit this irradiance and badly effect power output of solar PV module. The most prominent are soiling and shading due to surrounding environment. The most damaging one is the exposure of different cells to different irradiances which is called partial shading. The subject of partial shedding and its effects on Photo Voltaic (PV) system are receiving much attention of researchers. In order to model PV system in such conditions, and design a PV system that is immune and tolerant to the problem being addressed, several research articles have been reviewed in this study. Different techniques have been summarized and briefly described here, giving an insight to model PV system and mitigate the problem, with different tested configurations that are more effective in such conditions.
\end{abstract}

Keywords - Shading, Optical losses, Solar PV.

\section{INTRODUCTION}

There has been a tremendous shift from Carbon fuels consumptions to renewable energy which is environmentally friendly. This give a top spot to solar energy in today's widely used renewable energy sources, which is abundant, free and of extremely large potential. Transformation of this solar energy could be done in many ways but the most user friendly and affordable solution is photovoltaic systems. Photovoltaic modules used for this purpose can be managed easily and the end user is able to extract power of it by installing and managing simply without a lot to worry about maintenance. Whereas harnessing from other renewable energy sources involve complex systems that need an organized structure and deep knowledge to interact with such systems.

With the advent of latest inverter technology local consumer is able to connect its solar PV system to grid and thus can sell extra power to power utility companies. This benefit has increased PV system penetration in both rural as well as urban areas. Limited and costly lands in urban area result in too densely located houses and offices with PV modules on their roof top very nearly placed. Such environment is surrounded with tall buildings, chimneys, trees,dust, birds' droppings that blocks sunlight from equally falling on every module or even each cell in a same module. Single PV cell when receives solar irradiance give current and voltage. At temperature of $25 \mathrm{oC}$ and $1.5 \mathrm{AM}$ illuminations single silicon solar cell give 0.5 to $0.6 \mathrm{~V}$ across its two terminals. [1]. All the application involving electricity consumption required a voltage higher than one cell can provide. However, it can be made useful if many such cells are cascaded together in series and parallel configuration based on the need and demand of required load and application. In order to optimize the performance of pv module cells need to be electrically matched with same currents and voltages across each cell terminal for both series and parallel combinations [2]. Even if diligence is practiced in connecting the cells together still the problem exists if different cells receive different intensity of lights. If all the cells receive equal intensity light then no such problem arise but that is the ideal condition which is not always the case. In a situation when sunlight is blocked from a cell or group of cells then hotspot is created. Such cells start acting as a load thereby consuming some power from nearby cells. This can further aggravate the problem by heating those cells which receive little or no sunlight and thus limiting the power from those cells which receive enough sunlight and thus causing partial shading to happen.

'Power output of the whole PV system is reduced when system is exposed to partial shading. It is hard to track the absolute maximum power point when partial shading causes the system to detect many local maximum power points. Such shortcomings make the need to bring immunity in PV system more important in order to improve the power output of such systems. Such design needs to disconnect those cells that receive lesser light in order to avoid those cells from limiting their power that generate enough power if isolated from shaded cells. This will bring extra safety feature to the PV module by saving module from heating up too high. This is the common objective to mitigate partial shading problem which can be achieved through number of techniques. However, all techniques follow the same basic rule to bypass these shaded cells.

The first step is to model the PV system properly and then predict the shading patterns the module or group of modules is 
exposed to. Then bypassing those shaded cells are of much importance through bypassing devices by keeping power loses in these devices to the minimum. These cells can be bypassed in number of ways. The use of bypass diodes has attracted quite attention and that's why all commercially available modules practice this technique [3].

This paper investigates and reviews different techniques, modelling of cells and modules, different shading conditions, effectiveness of different techniques against different shades.

In Section 2 circuit modeling has been discussed and also a brief overview of the tools and software's used by different studies. Section 3 analyses different studies done by different researchers and their contributions to mitigate the problem of partial shading.

\section{CIRCUIT MODLING}

In order to model PV circuit first single PV cell is modeled either with single or two diode model. A set of equations is used to model behavior of single PV cell and different elements of basic electrical circuits, such as resistors in series and parallel and diodes are used. The easiest way is to model cell with single diode as it almost gives nearly same responses as two diode model could provide with ease and simplicity in its design [2] [4] [5]. Series Rs and Shunt resistance $\mathrm{Rp}$ is also included in the model by most studies to consider the losses attached to them. The equivalent circuit of PV cell can be seen in Figure.1 [2]. Where Jphoto , Jdark represent photocurrent and saturation current density respectively. Vout represents cell's terminal voltage.

In order to meet current and voltage requirements modules are formed by interconnecting these cells in series and parallel fashions. [5] is:

1 represent the principle equation of fig 1 as mentioned by

$\mathrm{J}_{\text {out }}=\mathrm{J}_{\text {photo }}-\mathrm{J}_{\text {sat }}\left\{\exp \left[\mathrm{q}\left(\mathrm{V}+\mathrm{J}_{\text {out }} \mathrm{Rs}\right) / \mathrm{nkT}\right]-1\right\}-\mathrm{V}+\mathrm{J}_{\text {out }} \mathrm{R}_{\mathrm{s}} / \mathrm{R}_{\mathrm{sh}}$

$$
\begin{aligned}
& \mathrm{q} \text { Represents electronic charge } 1.6 \times 10-19 \mathrm{C} \\
& \mathrm{k} \text { is Boltzmann constant }=1.38 \times 10-23 \mathrm{~J} / \mathrm{K}
\end{aligned}
$$

\section{$\mathrm{T}$ the cell temperature in $\mathrm{K}$}

In order to make such study easier simulations has been preferred because it saves time with the ease to simulate the varying uncontrolled environmental conditions of different temperatures and irradiances. Further, such simulation software's can enhance the study by observing different shades patterns. Different tools have been used in different studies: [5]-[8] uses LTspice, some authors have used Pspice [6], [7], Matlab and Simulink is also used to study PV cells [8], few studies prefer Python for simulation when these modules are exposed to different shading condition[9], [10]

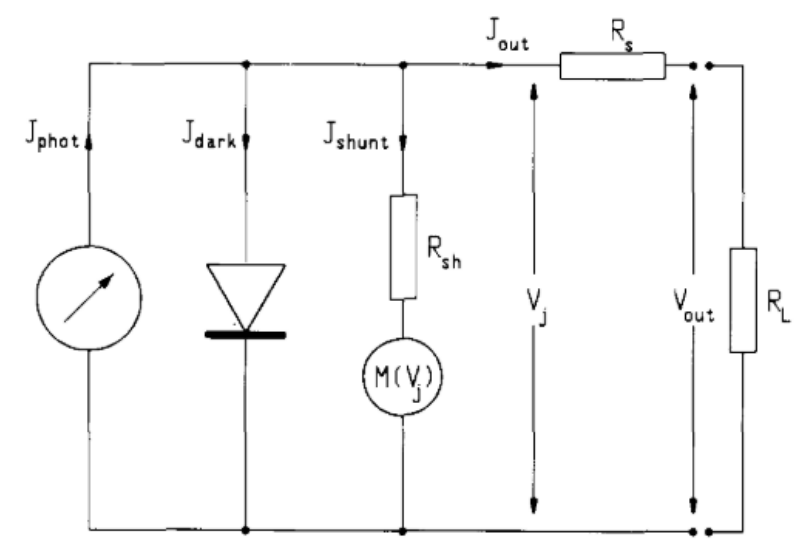

Figure 1. Solar Cell equivalent Circuit

\section{TECHNIQUES TO OVERCOME SHADING}

Number of techniques are currently being studied in order to solve the problem of partial shading. The most prominent and prolific one is the use of bypass diode. In such technique diodes are connecting across a cell or group of cells called strings and bypass them when they no more generate power or generate less power than other strings in the same modules [3]. Integrated diode in each cell is also used by [11]. Evidently, literature has also some studies which consider that bypassing of shaded cells can be done if cell junction breakdown voltage is controlled and reduced having the same effect as of bypass diodes [2]. Application of Power MOS Switches with cool bypass switch (CBS) is also proposed as can be seen in the study carried out by [12] bringing power losses from $4 \mathrm{~W}$ to few $\mathrm{mWs}$ by replacing Schottky diode with these CBS switches. Series parallel paths in a module can enhance immunity against partial shading, such claim is proved by a study in which full and halved cells are compared [13].

[14] studies shading's effects for photovoltaic (PV) module and photovoltaic-thermal (PVT) where simulation has been done with LTspice and then results are validated with experimental study, Solarus $\mathrm{AB}$ module is studied and investigated for this purpose. Temperature affects maximum power Pmax , maximum voltage Vmax and open circuit voltage Voc greatly whereas temperature affects maximum current Imax and short circuit current Isc little when it is prone more to irradiance[14]. [15] studies different shading patterns for a single cell experimentally. The same study suggests that monocrystalline module is not as much affected by partial shading as do multi crystalline silicon cells [15].

For an array having many connected modules in series, if a cell or number of cells get shaded then the power output will depend on string size. Otherwise, the shaded cell will dissipate nearly twice the power produced by module if it is not bypassed with diode or any other bypassing device [16]. For every 1 A decrease in current for each cell, maximum power reduced by $0.4 \mathrm{~W}$ with a decrease in Voc and temperature rise for all shading conditions [7]. Power decreases by $11-12 \%$ when there is a rise of $250 \mathrm{C}$ in temperature [7]. When a cell is completely shaded, then module with more bypass diodes is more efficient then the one having little number of diodes [17]. 
However, number of diodes is not always immunity measuring factor i.e. when part of a module is shaded by a constantly moving shadow of certain pattern, then efforts are needed to configure bypass diodes in effective way [17]. The best practice is to consider a diode configuration that is more shade resilient for a shade pattern already known and can be predicted. In [7], bypass diodes and blocking diodes' effects has been studied for an array with 3 rows and 20 modules in total when subjected to four different shading patterns.

In [4] effects a module with single and multiple shaded cells has been investigated, and IV curves are studied after exposing cells to shading and changes in IV curves are noted. [4] is used by author to diagnose fault in PV power generating system. Therefore, those primary factors can be observed which contribute to these losses upon observing the changes that occur in characteristics of IV curves [4]. Another study suggested by [18] is "hotspot prevention technique" in order to detect faults in case of partial shading. "Active fault tolerant control" can also be used to detect faults by observing and detecting closely positive peaks, and the contribution of nonuniform shadow in appearance of hotspot [18].
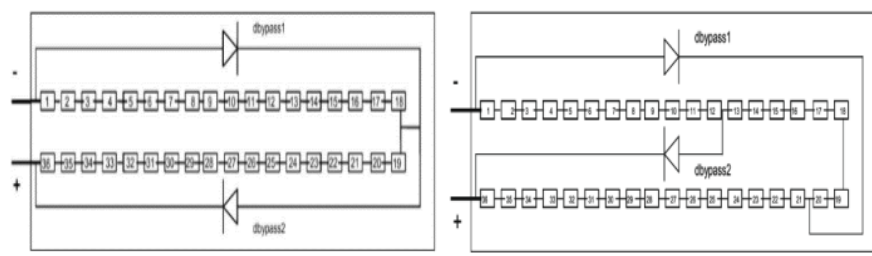

Figure 2. Equivalent circuit of PV module with two bypass diodes. (a)Nonoverlapped cells (b) overlapped cells

In [19] PV cells and modules are modeled and simulated with PSPICE and then impacts on these designs are noted for different possible configurations of bypass diodes. Simulation results are compared with experimental result in [19]. In the same study two bypass diodes' model has been compared for 36 cells: One with overlapping cells and another without overlapping cells as shown in fig 2 [19]. Different observations have been made, for single and two shaded cells with overlapping and non-overlapping diodes [19]. Such study is useful in deciding an optimized configuration of bypass diodes, an expression has also been proposed that can help in deciding number of cells that could be protected by single bypass diode [19].

In [11], shading patterns has been observed for two types of cell structures: Type A and Type B. Type A has diode integrated in its cell while type B does not have such integrated diode. The tolerance of both types is experimentally quantified. When single cell is shaded with less than $10 \%$ shade, both types almost perform in similar way [11]. As shading keep on increasing Type A perform better and more resilient to shade i.e. $50 \%$ shading of a single cell contribute $40 \%$ loss in type B system while the same shading adds losses to only $4 \%$ in type B system [11]. For $100 \%$ shade, the losses in system A are 20 times lower than that of system B [11].
[20] explains the minimum distance and tilt angle that is needed among PV modules in an array as shown in fig 3 in order to avoid shade of one row over another.

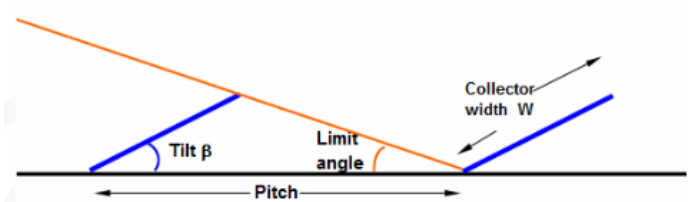

Figure 3. Reprensentation in row arrangement

$\mathrm{W}=$ row active width

$\beta=$ plane tilt angle

$\mathrm{P}=$ pitch between rows.

LimAngle $=\operatorname{ArcTan}(\mathrm{W} \cdot \cos \beta /(\mathrm{P}-\sin \beta))$

Occupation ratio $=\mathrm{OR}=\mathrm{W} / \mathrm{P}$

Occupation ratio does not depend on limit angle; it depends on tilt angle though [20].

In fig 4 comparison of different shadows can be seen on full and half cells. It is proved by [13] that 72 cells module is not affected by direction of shading. However, halved cells' module has improved result for shade moving vertically but this same module performance is exacarbated for shade that moves in X-direction [13]. Another such study uses half cells which shows that short circuit current increases to $3 \%$ and fill factor increases to nearly 1.48 percent while a decrease in losses has been noted from $8 \mathrm{~W}$ to $2 \mathrm{~W}$ due to decrease in series resistance value [21]. Furthermore, this study suggests use of single bypass diode across two strings of half cells [21]. The direction of moving shade has no such impact on module of standard cells [21]. However, half cells' module shows different behaviour to vertical and horizontal shade with better immunit for horizontal shades [21]. Half-cells module have the potential of minimizing losses due to shading to 50 percent at partial shading condition[21].
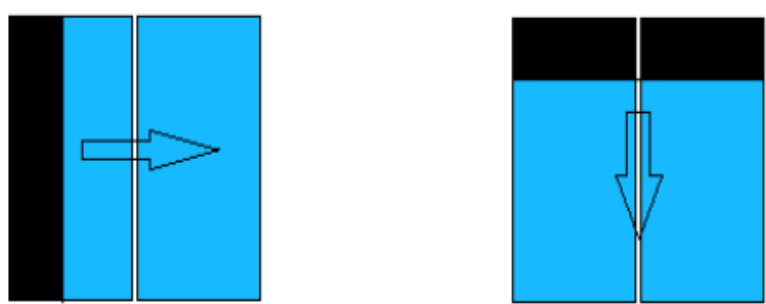

Figure 4. Effect of shadow on Full and Halved cells from two directions: (a) $\mathrm{X}$ direction (b) $\mathrm{Y}$ direction

PV industry has categorized Cells into two different categories according to reverse breakdown voltage: Type A and Type B. For type A, reverse breakdown voltage of cell is greater than maximum power point (MPP) of string, whereas for Type B it is the other way [22]. In heavy shaded condition type B does not perform good, such as illumination level of 0 $\mathrm{W} / \mathrm{m} 2$ [22]. Type A also perform worst for illumination level equal to MPP power when it dissipates power equal to MPP 
power [22]. The cell dissipate different power related to its breakdown voltage; for lower reverse breakdown voltage less power is dissipated during mismatch. [22] experimenatlly prove the effectiveness of "open circuit protection" based on hotspot detection.

In [23], 52 different module cofingurations are studied based on simulation for shading patterns that are static and predictable, for number of bypass diodes with many parallel paths. For uniform illumination nearly each configuration behave in similar way, but those with more blocking diodes increases loses[23]. For variable illumination different parameters needs to be considered which affects the yield in a different way such as how PV modules are orientated? number of paths in parallel and number of bypass diodes. Configurations having shortest branches in the direction of movement of shade is better in its perforamnce than the rest [23]. As the number of bypass diodes increases energy yield increases. Two configurations stand out in its performances against 3 diodes series connected PV panel : the one with 5 parallel branches for landscape orientation, and another with 42 branches for portrait orientation[23]. Another such study supports the same idea of relationship between panel configurations and its effects; otuput power is reduced to $16.54 \%$ for series configuration and $6.03 \%$ for parallel configuration under same level of shading condition [24]. Another study based on static dispersion positioning (SDP) in order to reduce those partial shading loses that closely depend on direction of shading [25]. This technique without bringing any change in electrical configuration distributes partial shading effects in whole array. In [25] this technique is compared with all known topologies and based on the results this technique proved better in its performance, with $13 \%$ improvement.

In [26], bypass diode is replaced with NMOS-based Integrated Modular Bypass (NIMBUS). NIMBUS is a smart switch that detect a failing cell when subjected to shading, and then activated upon requirement. It has small losses attached to them as compared to conventional diode [26]. Such switches can be combined together in parallel in order to handle larger current than that could be handled by single NIMBUS [26]. The optimum number of cells are grouped together, and with buck converter in place current is increased whenever there is a shade for a particular group [27]. This architecture is tested for different shading patterns and the result are quite attractive with $47 \%$ and $13.4 \%$ increase in average energy generation from that of series and parallel connected cells respectively [27].

\section{CONCLUSION}

This paper presents in depth review of mitigating the problem of partial shading. Different studies suggest different methods and techniques to overcome the problem of partial shading. This review includes the information of simulation tools used in any study and wherever applicable their experimental data too. For already known shading patterns, a specific kind of modules should be used particular to that shading pattern and direction. Efforts are needed to solve the addressed problem with a solution, which is neither expensive nor complex without dissipating too much power.

\section{AACKNOWLEDGMENT}

The authors wish to thank the researchers whose literature has been cited in this article and author providing materials and experimental setups used in this study. Research leading to this article was supported by the research grants of U.S.-Pakistan Center for Advanced Studies in Energy (USPCAS-E), University of Engineering and Technology (UET) Peshawar, Photovoltaic Reliability Lab (PRL ASU).

\section{REFERENCES}

[1] "Module Circuit Design | PVEducation." [Online]. Available:https://www.pveducation.org/pvcdrom/modules/modulecircuit-design. [Accessed: 02-Jun-2018]

[2] J. W. Bishop, "Computer simulation of the effects of electrical mismatches in photovoltaic cell interconnection circuits," vol. 25 , pp. 73-89, 1988.

[3] C. Gonzalez and R. Weaver, "Circuit design considerations for photovoltaic modules and systems," in 14th Photovoltaic Specialists Conference, 1980, pp. 528-535.

[4] H. Kawamura, K. Naka, N. Yonekura, S. Yamanaka, H. Kawamura, and H. Ohno, "Simulation of I $2 \mathrm{~V}$ characteristics of a PV module with shaded PV cells," vol. 75, pp. 613-621, 2003.

[5] S. Guo, F. J. Ma, B. Hoex, A. G. Aberle, and M. Peters, "Analysing solar cells by circuit modelling," Energy Procedia, vol. 25, pp. 28-33, 2012 .

[6] M. Lotfi, D. Zohir, and A. Electronic, "Modeling, Simulation and Implementation of PV Cell / Modules Using PSpice,"' vol. 9, no. 3, pp. $1-5,2017$.

[7] R. Rathee, V. Khanna, and B. K. Das, "Spice Based Modelling and Simulation to Study the Effects of Partial Shading on PV Array Characteristics," vol. 2, no. 5, pp. 68-73, 2013

[8] R. P. Vengatesh and S. E. Rajan, "Analysis of PV module connected in different configurations under uniform and non-uniform solarradiations,” Int. J. Green Energy, vol. 13, no. 14, pp. 1507-1516, 2016.

[9] B. B. Pannebakker, A. C. De Waal, and W. G. J. H. M. Van Sark, "Photovoltaics in the shade: one bypass diode per solar cell revisited," no. May, pp. 836-849, 2017.

[10] E. Science and C. Details, "Master Thesis - Final Report."

[11] S. Cells and R. December, "shadow tolerance of modules incorporating $i$ $\mathrm{n} \mathrm{t} \mathrm{e} \mathrm{g} \mathrm{r}$ a 1 the module or array. It is not surprising that this causes the rapid overheating of the cell and module destruction. The standard technique to protect against the destructive effects of partial s," vol. 19, pp. 109-122, 1987.

[12] S. Pennisi, F. Pulvirenti, and A. La Scala, "Low-Power Cool Bypass Switch for Hot Spot Prevention in Photovoltaic Panels," vol. 33, no. 6, pp. 880-886, 2011.

[13] F. Lu, S. Guo, T. M. Walsh, and A. G. Aberle, "Improved PV Module Performance Under Partial Shading Conditions," Energy Procedia, vol. 33, pp. 248-255, 2013.

[14] S. K. Nashih, C. A. F. Fernandes, J. P. N. Torres, J. Gomes, and P. J. Costa Branco, "Validation of a Simulation Model for Analysis of Shading Effects on Photovoltaic Panels," J. Sol. Energy Eng., vol. 138, no. 4, p. 044503, 2016.

[15] W. B. Xiao, F. Y. Hu, H. M. Zhang, and H. M. Wu, "Experimental investigation of the effects of partial shading on photovoltaic cells' electrical parameters," Int. J. Photoenergy, vol. 2015, 2015.

[16] A. Mermoud and T. Lejeune, "Partial shadings on PV arrays: By-pass diode benefits analysis," Eur. Photovolt. Sol. Energy Conf., pp. 6-10, 2010 .

[17] S. Guo, T. M. Walsh, A. G. Aberle, and M. Peters, "Analysing Partia Shading of PV Modules by Circuit Modelling $\S$ L voltage [ V ]," pp. 2957-2960, 2011

[18] M. Bressan, A. Gutierrez, L. G. Gutierrez, and C. Alonso, "Development of a real-time hot-spot prevention using an emulator of partially shaded PV systems," Renew. Energy, 2018. 
[19] S. Silvestre, A. Boronat, and A. Chouder, "Study of bypass diodes configuration on PV modules," Appl. Energy, vol. 86, no. 9, pp. 1632 1640, 2009.

[20] A. Mermoud, "Optimization of row-arrangement in PV Systems, shading loss evaluations according to module positioning and connexions," 27th Eur. Photovolt. Sol. Energy Conf., no. September, pp. $24-28,2012$.

[21] H. Hanifi and J. Schneider, "reduced shading effect on half-cell modules - measurement," no. February 2018, 2015.

[22] K. A. Kim and P. T. Krein, "Reexamination of Photovoltaic Hot Spotting to Show Inadequacy of the Bypass Diode," vol. 5, no. 5, pp. 1435-1441, 2015.

[23] B. Lefevre, S. Peeters, J. Poortmans, and J. Driesen, "Predetermined static configurations of a partially shaded photovoltaic module," 2016.

[24] A. K. Tripathi, M. Aruna, and C. S. N. Murthy, "Performance of a PV panel under different shading strengths," Int. J. Ambient Energy, vol. 0, no. 0, pp. 1-6, 2017.

[25] P. R. Satpathy and R. Sharma, "Power loss reduction in partially shaded PV arrays by a static SDP technique," Energy, vol. 156, pp. 569-585, 2018.

[26] P. Bauwens and J. Doutreloigne, "NMOS-Based Integrated Modular Bypass for Use in Solar Systems ( NIMBUS ): Intelligent Bypass for Reducing Partial Shading Power Loss in Solar Panel Applications," 2016.

[27] M. Architecture, "Improvement of Shade Resilience in Photovoltaic Modules Using Buck Converters in a Smart," 2018.

[28] anocomposites, ACS Appl. Mater. Interfaces 6 (2014) 1415-1423. 